\title{
Agenesis of the Medial Gastrocnemius and Plantar Muscle. Case Presentation
}

\author{
Agenesia del Gastrocnemio Medial y del Músculo Plantar. Presentación de Caso
}

\author{
María Fernanda Álvarez ${ }^{1}$ Camilo Alfonso Bueno ${ }^{1}$ \& Luis Ernesto Ballesteros ${ }^{1}$
}

\begin{abstract}
ÁLVAREZ, M. F.; BUENO, C.A. \& BALLESTEROS, L. E. Agenesis of the medial gastrocnemius and plantar muscle. Case presentation. Int. J. Morphol., 35(1):34-36, 2017.

SUMMARY: We present the case of a left medial gastrocnemius and plantar muscle agenesis in a 58-years old male cadaveric specimen from the Anatomy Laboratory at the Universidad Industrial de Santander (Bucaramanga-Colombia). These unusual muscle absences and associated functional alterations, enrich anatomical knowledge and become important by the time the affected individual may need a reconstructive procedure.
\end{abstract}

KEY WORDS: Agenesis; Medial gastrocnemius; Plantar muscle

\section{INTRODUCTION}

Muscle agenesis is a rare anomaly, being the agenesis of palmar longus the most frequently reported in the literature, with an overall incidence of $15 \%$ (Htwe et al., 2012) (Sankar et al., 2011) and $13.1 \%$ in the Hispanic population (Soltani et al., 2012). As for the absence of the Medial Gastrocnemius Muscle (MGM), there is not sufficient evidence of its incidence and only have been described case reports, while Plantar Muscle (PM), is estimated to be 7-20 $\%$ (Aragão et al., 2010 \& Kwinter et al., 2010). The etiology of these muscle abnormalities can be divided into vascular, teratogenic, congenital or due to alterations in the development (Htwe et al.).

MGM and PM, along with the rest of the posterior compartment of the leg, are responsible for the entire movement of plantar flexion (Ballesteros Acuña \& Saldarriaga Tellez, 1998). However, agenesis that are usually described in this region, are of muscle heads that do not perform relevant biomechanical functions by themselves and therefore, tend to go generally unnoticed and asymptomatic clinically, becoming only evident in affected individuals on scenarios that require significant efforts, such as sports.

Existent information towards diverse variant expressions of the muscular structures in the inferior limbs benefits from studies about a variation in particular, while multiple variations observed in an individual must be reported as cases. Besides having an academic impact, it is important to know the associated functional alterations these variations imply, and how they could be significant in an affected individual who may need a reconstructive procedure.

\section{CASE REPORT}

We present the case of a 58-years old male cadaveric specimen from the Anatomy Laboratory at the Universidad Industrial de Santander (Bucaramanga-Colombia), set with a Chilean conservative fixative solution. Approach of the posterior compartment of the leg was done through an incision over the median line, from the gluteal fold until the calcaneus tendon insertion; separating fascial-cutaneous medial and lateral flaps. Later; vascular, muscular and nervous structures contained in the thigh and leg were dissected by plans.

The following anatomic variations were found: agenesis of MGM and PM in the left leg (Figs. 1 \& 2); Lateral Gastrocnemius Muscle (LGM) presented a proximal insertion in the posterior and superior surface of the lateral femoral condyle, while the distal insertion merged to the muscular head of the soleus. This muscular belly had a length of $19.8 \mathrm{~cm}$ width of $4.7 \mathrm{~cm}$ and thickness of $1.35 \mathrm{~cm}$. Sciatic nerve divided into tibial and common fibular once it entered to the popliteal

${ }^{1}$ Universidad Industrial de Santander, Colombia. 


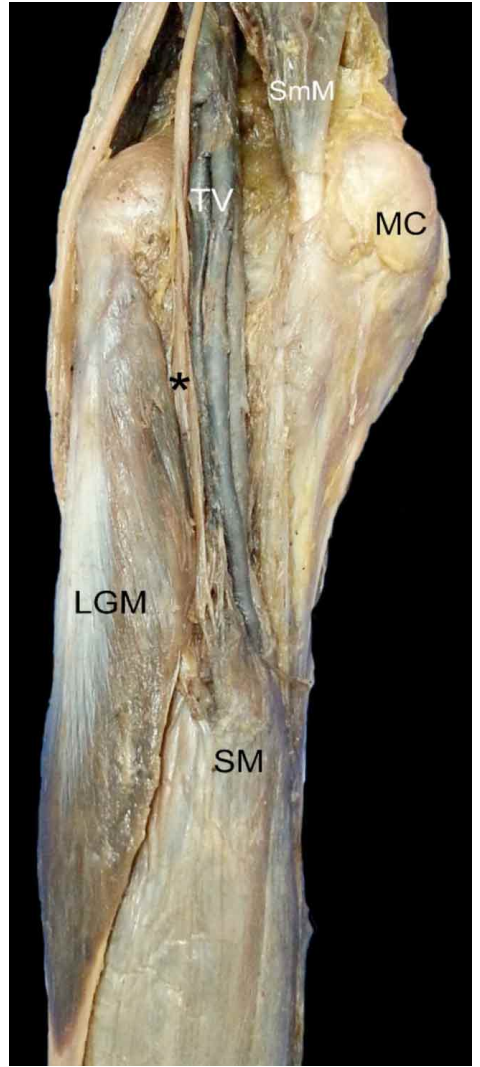

Fig. 1. Posterior view of a left knee and leg. Agenesis of the Medial Gastrocnemius and Plantar muscles. SmM. Semimembranosus muscle; TV. Tibial Vessels; $(*)$. Tibial nerve; MC. Medial condyle; LGM. Lateral Gastrocnemius muscle; SM. Soleus muscle.

region, the popliteal artery gave origin to the usual geniculated and muscular branches for the LGM and the popliteal vein received the correspondent tributaries. These neurovascular structures presented a descendant trajectory alongside the medial edge of the LGM, surrounded by moderate adipose tissue and the popliteal lymph nodes. The right inferior limb did not present muscular agenesis neither structural variations.

\section{DISCUSSION}

It is important to highlight, embryogenesis of appendicular striated skeletal muscle begins around the seventh week, and hence congenital muscular anomalies are due to a phenomenon occurring in this period of gestation. The process begins with the incipient formation of muscle buds composed of the mesenchyme that has migrated, and which will eventually form the muscles. These buds grow, elongating and being shaped out of the structure adapted by the connective tissue until their final disposition. Finally, the separation of fibers in antagonist groups occurs, such as flexors, extensors, abductors and adductors (Htwe et al.).

A research was conducted in the literature, finding that the unilateral isolated agenesis of MGM had not been previously reported, while the incidence of agenesis of the PM, is estimated to be present in 7-20\% of the population (Spina, 2007; Gopinath et al., 2012 \& Sawant et al., 2012). Also, concomitant agenesis of the two aforementioned muscles was not found, possibly because its absence does not determine a marked biomechanical disability in the inferior limb and can easily be unnoticed; that is why we consider this report as pertinent. Two case reports are worth distinguishing both in pediatric patients in the United Kingdom, who reported mild aesthetic and functional alterations without major impact in gait biomechanics. Agenesis of superficial posterior compartment was confirmed through magnetic resonance imaging, but not exactly discriminating whether it was full or partial (Htwe et al.; Kang \& Jang, 2014).

In contrast with the gastrocnemius agenesis, other variations in this muscle have been reported during routine anatomical dissections of cadaveric specimens, highlighting the presence of a third accessory head, which originates from the popliteal surface of the femur and distally inserts into the tendinous union of both gastrocnemii. In addition, other findings related to variants in origin, insertion, size and length of this muscle have been cited (Kim et al., 2008; Dave et al., 2012 \& Ashaolu et al., 2014).

A cadaveric specimen with a one-sided absence of a muscle in charge of $25 \%$ of plantar flexion, plus a normal soleus muscle, raises doubts about the daily physical activity limitations this may imply; besides aesthetic implications which are evident. It has been reported that the flexor and extensor action exerted by the sural triceps is essential in maintaining the center of gravity during standing (Héroux $e t$ al., 2014). Besides the biomechanical action of MGM and PM, they help protect nerves and vessels coursing through the popliteal region; therefore, risk of neurovascular lesion increases with the agenesis of these muscles. 
The different functions of each muscle from the posterior compartment of the leg during several positions have been accurately characterized by electromyographic recording. The lowest activity during the standing position is presented by the lateral gastrocnemius muscle, resulting that the threshold recruitment of its muscle fibers is up to 20 times greater than the MGM and 35 times than the soleus. Meanwhile, in standing position with posterior tilt, the MGM showed the highest activity (Héroux et al.); so it is inferred that its absence could certainly generate some degree of limitation.

Finally, it is important to stand out the use of PM tendon to perform some surgical reconstructive procedures, so its agenesis would lead to reformulate conventional surgical techniques (Ballesteros Acuña \& Saldarriaga Tellez). Among the procedures described in the literature, it is pertinent to note the reconstruction of various tendinous and ligamentous structures, such as joint ligaments of the foot (anterior talofibular, calcaneofibular) (Pagenstert et al., 2005) and flexor tendons; using its distal segment as osteotendinous grafts. This technique has been used for over 60 years, as it has proven good postoperative prognosis by the development of greater strength, mobility of the limb and better healing; over other types of grafts (Dos Santos et al., 2009).

In conclusion, muscle agenesis in lower limbs are rare and usually overlooked during routine physical examination, unless the aesthetic impact makes it evident. Likewise, it is important to promulgate these findings through case reports, as it allows the academic community to suspect them in the clinical scenery, to make a diagnostic approach and further exploration of the possible biomechanical implications for the patient.

ÁLVAREZ, M. F.; BUENO, C. A. \& BALLESTEROS, L. E. Agenesia del gastrocnemio medial y del músculo plantar. Presentación de caso. Int. J. Morphol., 35(1):34-36, 2017.

RESUMEN: Se presenta un caso de agenesia de los músculos gastrocnemio medial y plantar izquierdos en un espécimen cadavérico masculino de 58 años, del laboratorio de anatomía de la Universidad Industrial de Santander (Bucaramanga- Colombia). Estas raras ausencias musculares enriquecen el conocimiento anatómico con sus alteraciones funcionales concomitantes y permiten postular los posibles procedimientos reconstructivos requeridos en los individuos que las presentan.

PALABLAS CLAVE: Agenesia; Gastrocnemio medial; Músculo plantar

\section{REFERENCES}

Aragão, J. A.; Reis, F. P.; Guerra, D. R. \& Cabral, R. H. The occurrence of the plantaris muscle and its muscle-tendon relationship in adult human cadavers. Int. J. Morphol., 28(1):255-8, 2010.
Ashaolu, J. O.; Oni-orisan, O. A.; Ukwenya, V. O.; Opabunmi, O. A. \& Ajao, M. S. The quadriceps gastrocnemius muscle. Surg. Radiol. Anat., 36(10):1101-3, 2014.

Ballesteros Acuña, L. E. \& Saldarriaga Tellez, V. Consideraciones anatómicas de los músculos inconstantes. MedUNAB, 1(3):165-70, 1998.

Dave, M. R.; Yagain, V. K. \& Anadkat, S. Unilateral third/accessory head of the gastrocnemius muscle: A case report. Int. J. Morphol., 30(3):1061-4, 2012.

Gopinath, T. N.; Jagdish, J.; Krishnakiran, K. \& Shaji, P. C. Rupture of plantaris muscle - A mimic: MRI findings. J. Clin. Imaging Sci., 2:19, 2012.

Héroux, M. E.; Dakin, C. J.; Luu, B. L.; Ingnil, J. T. \& Blouin, J. S. Absence of lateral gastrocnemius activity and differential motor unit behavior in soleus and medial gastrocnemius during standing balance. J. Appl. Physiol. (1985), 116(2):140-8, 2014.

Htwe, O.; Swarhib, M.; Pei, T. S.; Naicker, A. S. \& Das, S. Congenital bilateral agenesis of the tibialis anterior muscles: a rare case report. Rom. J. Morphol. Embryol., 53(3):657-9, 2012.

Kang, J. Y. \& Jang, D. H. Congenital agenesis of the superficial posterior compartment calf muscles in a 13-month-old infant. Am. J. Phys. Med. Rehabil., 93(11):e1-5, 2014.

Kim, H. K.; Laor, T. \& Racado, J. M. MR imaging assessment of the lateral head of the gastrocnemius muscle: prevalence of segmental anomalous origins in children and young adults. Pediatr. Radiol., 38(12):1300-5, 2008.

Kwinter, D. M.; Lagrew, J. P.; Kretzer, J.; Lawrence, C.; Malik, D.; Mater, M. \& Brueckner, J. K. Unilateral double plantaris muscle: A rare anatomical variation. Int. J. Morphol., 28(4):1097-9, 2010.

Pagenstert, G. I.; Valderrabano, V. \& Hintermann, B. Lateral ankle ligament reconstruction with free plantaris tendon graft. Tech. Foot Ankle Surg., 4(2):104-12, 2005

Sankar, K. D.; Bhanu, P. S. \& Jhon, S. P. Incidence of agenesis of palmaris longus in the Andhra population of India. Indian J. Plast. Surg., 44(1):134-8, 2011.

Dos Santos, M. A.; Bertelli, J. A.; Kechele, P. R. \& Duarte, H. Anatomical study of the plantaris tendon: reliability as a tendo-osseous graft. Surg. Radiol. Anat., 31(1):59-61. 2009.

Sawant, S. P.; Shaikh, S. T. \& More, R. M. A rare variation of plantaris muscle. Int. J. Biol. Med. Res., 3(4):2437-40, 2012.

Soltani, A. M.; Peric, M.; Francis, C. S.; Nguyen, T. T. J.; Chan, L. S.; Ghiassi, A.; Stevanovic, M. V. \& Wong, A. K. The Variation in the Absence of the Palmaris Longus in a Multiethnic Population of the United States: An Epidemiological Study. Plast. Surg. Int., 2012:282959, 2012.

Spina, A. A. The plantaris muscle: anatomy, injury, imaging, and treatment. J. Can. Chiropr. Assoc., 51(3):158-65, 2007.

Corresponding author:

Dr. Luis Ernesto Ballesteros

A. Avenida González Valencia \#54.25 Apto. 404

Bucaramanga

COLOMBIA

E-mail: Iballest56@yahoo.es 